\title{
ESTUDIO DE “PRODUCTOS” LÍTICOS TALLADOS DE LA CALLE DOLORES QUINTANILLA (CARMONA, SEVILLA)
}

\section{STUDY OF THE LITHIC “PRODUCTS” FROM DOLORES QUINTANILLA STREET (CARMONA, SEVILLA)}

\author{
por \\ OLGA SÁNCHEZ LIRANZO
}

A mi profesor y amigo Enrique Vallespí

RESUMEN En este trabajo exponemos los resultados del análisis de los productos líticos tallados de una de las estructuras excavadas en Dolores Quintanilla (Carmona, Sevilla). El estudio de la tecnología lítica nos ayudará a inferir cuestiones fundamentales sobre los modos de vida de los seres humanos que habitaron Carmona en el III milenio antes de nuestra era.

\begin{abstract}
This work presents the results of the analysis of the lithics products from one of the excavated structures in Dolores Quintanilla (Carmona, Seville). The study of the litic tecnology will help us to infer fundamental questions about the way of the life of the human beings that lived in Carmona during the III milenium before our era.
\end{abstract}

\section{INTRODUCCIÓN}

La industria lítica tallada que aquí se presenta es parte del material recuperado de la excavación de urgencia realizada durante el verano de 1996 en la C/ Dolores Quintanilla nº 6 de Carmona (fig.1). 
Los productos ${ }^{1}$ líticos estudiados pertenecen a un "fondo de cabaña" (F1) del llamado normativamente "Cobre Pleno", excavado en el alcor, de planta circular (con un diámetro de 2,52 m) y con paredes ligeramente acampanadas. En el solar en el que se realizó la excavación se encontraron otras tres estructuras relacionadas con el llamado "fondo 1 " 3 .

Es cierto que es difícil aproximarse a la tecnología lítica únicamente a partir del análisis morfológico, técnico y tipológico (Pie y Vila 1992). Sin embargo, si consideramos que la industria lítica es el resultado de una actividad humana para satisfacer unas necesidades determinadas, podemos intentar inferir a partir de ellos cuáles eran los propósitos, si se satisficieron sus necesidades y de qué forma. Además, estos útiles nos permiten de alguna forma calibrar la fuerza de trabajo del grupo social, porque su creación implica una inversión de trabajo en su medio ambiente (Vargas 1990).

En este trabajo ${ }^{4}$ vamos a ocuparnos del estudio de la producción de instrumentos de trabajo, considerando por tanto "las actividades de talla lítica como una parte esencial del proceso productivo de una comunidad" (Mora et alii 1992: 177).

\section{INVENTARIO DE MATERIALES LÍTICOS TALLADOS (Gráfica 1)}

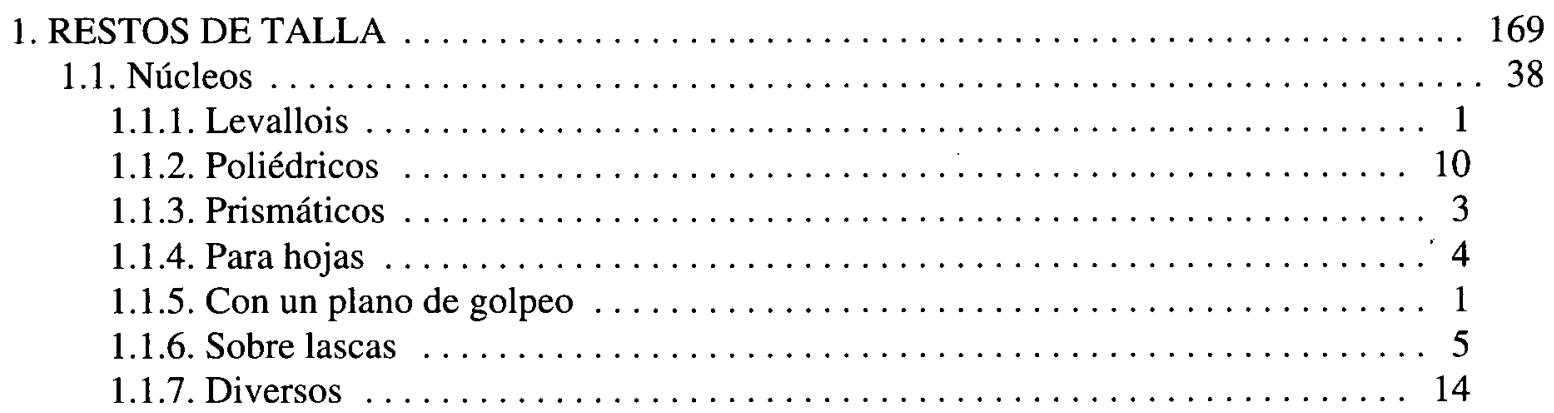

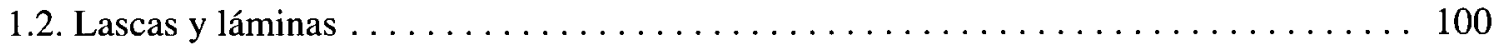

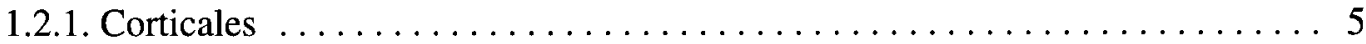

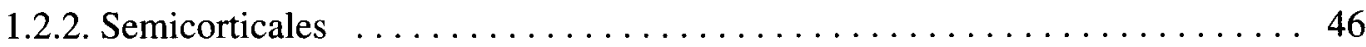

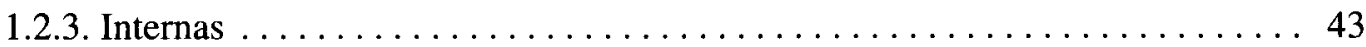

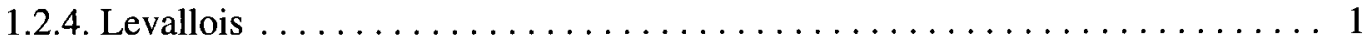

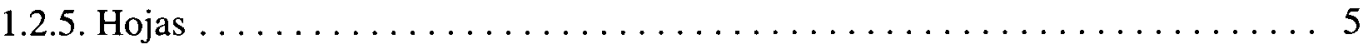

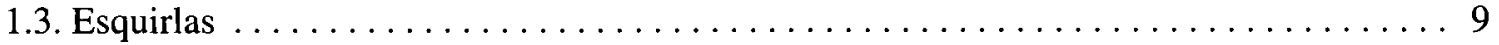

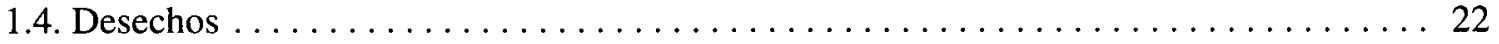

1. Un artefacto contextualizado arqueológicamente es un producto de un proceso socio-económico determinado (Ruiz et alii 1986). Esta perspectiva de los artefactos como productos permite vincular el aspecto tecnológico en el marco de las relaciones sociales (Ruiz et alii 1986; Ramos et alii 1992).

2. En los niveles pertenecientes a la llamada "Edad del Cobre" no ha aparecido ningún nivel de ocupación. Los útiles se encontraban rellenando la estructura estudiada, de ahí que se haya realizado el análisis de la industria lítica como una sola unidad, en la que ha sido imposible realizar alguna asociación a nivel espacial.

3. Según los datos que aportaron Juan Manuel Román Rodríguez y Elizabeth Conlin Hayes, pertenecientes al equipo de investigación de Carmona, dirigido por la prof. Dr. María Belén Deamos. A todos ellos quiero agradecer su colaboración y el hecho de haberme dado la posibilidad de estudiar este material.

4. El interés por la industria lítica tallada debe enmarcarse en la línea de trabajo iniciada por el profesor Enrique Vallespí en Andalucía Occidental, donde antes era prácticamente inexistente. En la misma línea se encamina la obra de José Ramos, entre cuyos méritos está el haber sabido aunar a un grupo de jóvenes investigadores/as en el ámbito académico gaditano. A ambos debo no sólo el entusiasmo por la industria lítica, sino también el carácter crítico y optimista que han transmitido. 


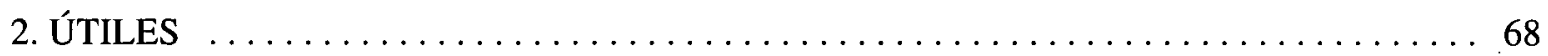

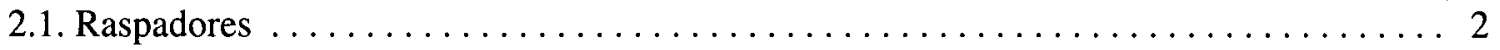

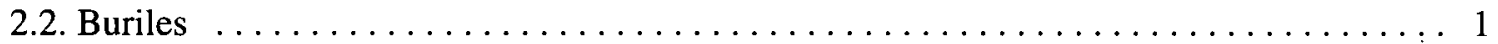

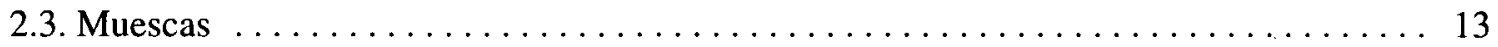

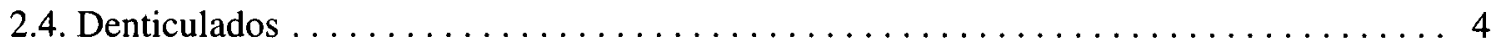

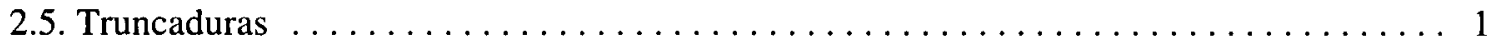

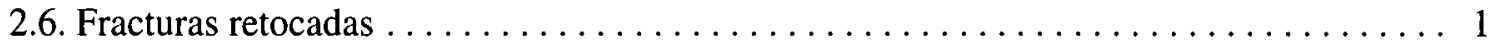

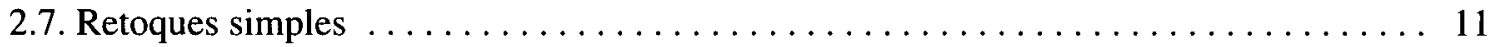

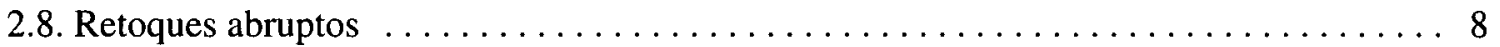

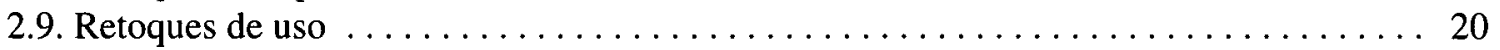

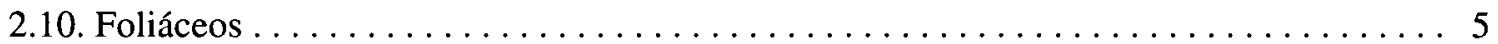

2.10.1. Puntas . . . . . . . . . . . . . . . . . . . . . . . . . . 2

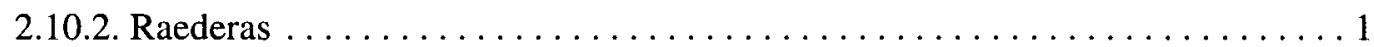

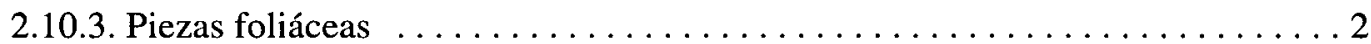

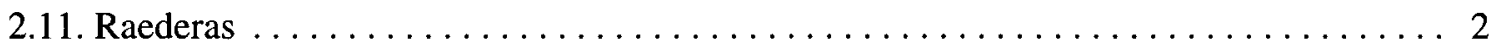

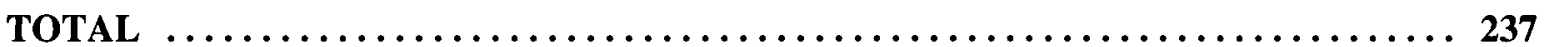

\section{ANÁLISIS MORFOLÓGICO Y TÉCNICO DE LA INDUSTRIA LÍTICA TALLADA}

\subsection{Materias Primas 5 y Rodamiento (Gráfica 2)}

La cuarcita es la materia prima predominante $(46,69 \%)$, en general de buena calidad, de colores variados, abundando los grises, marrones claros y rojizos. Los útiles sobre rocas silíceas son menos abundantes $(38,97 \%)$. Destacan los colores marrones, grises y ocres.

El cristal de roca tiene una escasa pero significativa representación (10,29\%). Algunas piezas se encuentran tan alteradas que es difícil determinar si su fractura es intencional o natural y a veces incluso si reciente $o$ antigua. Es evidente, al menos, que es una materia prima exógena, que ha sido transportada, no sabemos de dónde, hasta este lugar.

Podemos observar que la mayoría de los núcleos y lascas y láminas sin retoques están sobre cuarcita. En cambio, en los útiles la materia prima predominante es la roca silícea (63\%), cuestión que interpretamos por la abundancia de cuarcita en el valle del Guadalquivir. Los útiles sin embargo, piezas más elaboradas, se realizan sobre rocas silíceas cuya presencia en el valle es menor.

No podemos asegurar cuál es la procedencia de la materia prima, usada por estos grupos humanos para fabricar sus instrumentos porque para ello lógicamente necesitaríamos apoyarnos en el estudio petrológico del material (Domínguez-Bella et alii 1995; Terradas 1995). Este tipo de información nos ayudaría a desarrollar cuestiones muy interesantes sobre obtención, distribución, intercambio y consumo de materias primas.

La industria se presenta poco rodada, tan sólo el $11 \%$ tiene un rodamiento importante.

5. Esta primera clasificación es provisional y tendrá que ser revisada por petrólogos. De hecho algunas materias primas no las hemos podido identificar. 


\subsection{Tecnología}

\subsubsection{Plataformas de percusión}

Hemos contabilizado las plataformas de percusión de toda la industria lítica (restos de talla y útiles). Los talones reconocibles (52\%) se igualan prácticamente a los talones "abatidos" (47\%) (aquellos que son imposibles de reconocer porque han sido eliminados). Por tanto es fundamental tener en cuenta las limitaciones que presenta este análisis.

Se han computado, además, los talones en función de la existencia de talones reales, es decir sin contabilizar los abatidos (Gráfica 3). De los talones reconocibles predominan los corticales (46\%). Esto se debe a que la industria está principalmente realizada sobre soportes de cantos rodados de cuarcita, cuyo tamaño es más bien reducido. El soporte elegido condiciona que la mayoría de los restos de talla y útiles tengan presencia de cortex.

Los talones lisos abundan más en los restos de talla (30\%) que en los útiles (14\%). A continuación le siguen los facetados (14\%), y en menor medida los puntiformes y diedros. Sin embargo, los útiles con talones facetados (22\%) superan a los lisos (14\%), éstos igualados a los diedros (Gráficas 4 y 5).

Es interesante resaltar cómo los restos de talla y los útiles presentan un porcentaje de talones abatidos semejantes (restos de talla $47 \%$ y útiles $48 \%$ ); sin embargo las razones pensamos que son bien distintas. En el caso de los restos de talla se debe a su elevado grado de fracturación; en cambio, en el de los útiles a que el retoque ha eliminado el talón.

\subsubsection{Tipometría ${ }^{6}$ general de la industria}

En este apartado hemos introducido, igual que José Ramos (1991-1992: 46) el estudio tipométrico de la industria lítica en su globalidad. Somos conscientes, por tanto, de la enorme limitación que muestra el análisis tipométrico de Bagolini, que sólo es aplicable a los restos de talla.

No hay una tendencia laminar en el conjunto. Predominan las lascas, tanto en los porcentajes totales (80\%) como en los porcentajes de las piezas completas (22\%). Es evidente la relación entre la tipometría de la industria y el tipo de soporte que los grupos humanos usaron.

No pasa desapercibida la enorme fracturación de la industria (73\%). De hecho sólo tenemos completos sobre láminas dos útiles y cuatro restos de talla.

El alto grado de fracturación de la industria lítica es un obstáculo para realizar el análisis dimensional propuesto por Bagolini (1968). La clasificación según las dimensiones de los restos de talla completos son las siguientes: 3 microlascas, 3 microlascas anchas, 2 microlascas muy anchas, 3 microlascas laminares, 2 microláminas, 2 pequeñas lascas, 1 pequeña lasca laminar, 1 lasca muy ancha, 3 lascas, 1 lasca muy ancha, 2 lascas laminares y 1 lámina.

Se puede observar que son pequeños, medianos y muy pequeños los elementos líticos de los que tenemos una mayor representación.

De todo este estudio sobre la tipometría general de la industria lítica se pueden extraer las siguientes ideas:

- No abundan las láminas. Posiblemente se deba al tipo de soporte que principalmente se usa, la cuarcita de canto rodado que no permite fabricar piezas de gran tamaño.

6. El análisis tipométrico se puede realizar por dos vías complementarias: una, mediante la cuantificación, es decir por métodos estadísticos (Mora et alii 1992); y otra, a partir del tradicional análisis cualitativo (Bagolini 1968). En nuestro estudio debido al escaso número de piezas cuantificadas no se puede aplicar el método estadístico. 
- El tamaño de los elementos de sílex, salvo algunas excepciones, es también pequeño. Ello puede explicarse tanto por el máximo aprovechamiento de esta materia prima, que escasea en los alrededores de Dolores Quintanilla, como por su procedencia en forma de nódulos de sílex.

— Los restos de talla son medianos, pequeños y muy pequeños, según el análisis tipométrico de Bagolini.

- Es escasa, pero significativa, la presencia de hojas como elemento que confirma la talla a presión.

\subsubsection{Tipos de núcleos ${ }^{7}$}

Hay 18 núcleos. Ello supone el 16\% del total de la industria lítica del yacimiento, con una tipología muy variada (Gráfica 6). Los más abundantes son aquellos que se han clasificado en la categoría de los "diversos" (42\%). Aquí se han incluido algunos fragmentos de piezas pulimentadas (molinos) con algunas extracciones que pensamos que son intencionales. A continuación les siguen los poliédricos y los núcleos sobre lascas, que son los que mejor se adaptan a la morfología de los cantos rodados. Importante es la presencia, aunque mínima, de un núcleo levallois y de núcleos para hojas (10\%).

El tamaño de las extracciones indica que las lascas extraídas son de mediano y pequeño tamaño, coincidiendo con la tipometría general de los restos de talla. La mayoría de los núcleos tienen planos de golpeo corticales y lisos, en armonía con los porcentajes de los tipos de talones (corticales y lisos) de los restos de talla y útiles.

Los núcleos sobre cuarcita son mayores que los de sílex (Gráfica 7). Esta cuestión ya se ha tratado anteriormente y nos sugiere la hipótesis de un acceso diferente a la materia prima, así como del tipo de soporte que se utiliza.

\subsubsection{Restos de talla ${ }^{8}$}

Se ha analizado un total de 100 lascas y láminas sin retocar. La gráfica 8 refleja el porcentaje de los tipos de lascas que se han extraído de los núcleos. En las lascas y láminas sin retocar, los tipos más numerosos son las semicorticales (46\%) y las internas (43\%). Escasa es la presencia de lascas levallois (sólo un ejemplar) y de las hojas.

Observamos el porcentaje de los tipos de lascas y láminas, tanto retocadas como sin retocar (Gráficas 8 y 9). Vemos por tanto, cómo en los útiles son más abundantes las lascas que necesitan de unas técnicas algo más elaboradas que las de las lascas semicorticales, como son las internas y las hojas. A pesar de ello, las diferencias no son considerables.

\subsubsection{Conclusiones. Técnicas de talla documentadas}

De los estudios realizados anteriormente se pueden extraer las siguientes conclusiones:

7. Según el Sistema Lógico Analítico son "Bases Negativas de Primera Generación" (BNIG).

8. Según el Sistema Lógico Analítico se denominan "Bases Positivas de Primera Generación" (BPIG). El uso de la terminología empleada por el S.L.A. nos parece más adecuada que la tradicionalmente usada, en concreto porque elimina el uso de términos de "restos de talla" y "útiles" que difícilmente se adecuan a la realidad y permite eliminar ciertas "etiquetas". La denominación resto de talla elimina a priori cualquier posibilidad del uso de lascas y láminas sin retoques como instrumentos de trabajo. 
- La técnica de talla documentada va a estar íntimamente relacionada con la presencia mayoritaria de los núcleos sobre cuarcita. Se usan principalmente cantos rodados de río, de ahí que la técnica de talla sea muy simple en este caso, pero efectiva para las extracciones de lascas. De hecho, gran parte de los núcleos son poliédricos y diversos (sin una morfología determinada). Es interesante el escaso agotamiento de los núcleos sobre cuarcita y la presencia de cortex en la mayoría de los restos de talla que apoyan la idea de la abundancia de cuarcitas en el entorno de Carmona.

- En el caso de las rocas silíceas, los núcleos $(21 \%)$ van a tener un comportamiento bien distinto. Sólo 2 de los 8 núcleos tienen cortex . Esto nos puede indicar que nos encontramos con una materia prima no muy abundante, y que por tanto se aprovecha al máximo.

- Para la talla se usan principalmente las zonas corticales (talón cortical) como plano de golpeo de los núcleos de cantos rodados de río.

- El gran número de talones lisos sugiere la existencia de unos planos de golpeo lisos en los núcleos (núcleos con planos de golpes preparados, prismáticos y poliédricos).

- Es evidente el empleo de percutores duros para la talla de la mayoría de los núcleos sobre cuarcita. Sin embargo, tenemos también algunos elementos que nos indican el uso de una talla mucho más elaborada y delicada, aunque minoritaria, como puede ser el empleo de la talla a presión muy característico de la Prehistoria Reciente para la extracción de hojas. Los talones puntiformes, los núcleos para hojas y las hojas pueden confirmar el empleo de esta técnica para fabricar un tipo determinado de instrumentos de trabajo. Por tanto, se puede concluir este apartado sobre las técnicas de talla, asegurando que estos grupos humanos dominan bien distintas técnicas de talla, que usan según el instrumento de trabajo que pretendan fabricar.

\section{ANÁLISIS TIPOLÓGICO}

\subsection{Cómputo general de los restos de talla y útiles (Gráfica 1)}

Es interesante el peso significativo de los restos de talla (71\%), que supera al de los útiles (28\%). Hay una relación directa entre los porcentajes y la funcionalidad de la estructura ("fondo de cabaña"). Pensamos que en ella se ha producido parte del proceso de transformación de la materia prima en útiles. Nos apoyamos en los porcentajes de núcleos y restos de talla, así en algunos nódulos de cuarcita y sílex aparecidos. Sin embargo, el porcentaje de útiles es también indicativo del uso de este lugar como área doméstica.

\subsection{Cómputo General de los útiles ${ }^{9}$ (Gráfica 10)}

Se ha realizado el cómputo general de los útiles, tanto por grupos como del total de la industria. Destacan como los más numerosos los útiles con retoque simple y con retoques de uso. También es importante el grupo de las muescas, aunque este porcentaje debe usarse con mucha cautela.

9. Según el Sistema Lógico Analítico serían "Bases Negativas de Segunda Generación” (BN2G). 


\subsection{Análisis de los útiles por grupos "culturales"}

\begin{tabular}{|l|c|c|}
\cline { 2 - 3 } \multicolumn{1}{c|}{} & $\mathrm{N}^{\circ}$ & $\%$ \\
\hline $\begin{array}{l}\text { 1.- Útiles de tradición paleo-epipaleolítica (raspadores, buriles, raederas, perforadores } \\
\text { buriles, truncaduras y fracturas retocadas) }\end{array}$ & 7 & 10,29 \\
\hline 2.- Muescas y denticulados & 17 & 25,00 \\
\hline 3.- Lascas y láminas retocadas & 39 & 57,35 \\
\hline 4.- Útiles característicos del Cobre y Bronce & 5 & 7,35 \\
\hline \multicolumn{1}{|c|}{ TOTAL } & 68 & 100,00 \\
\hline
\end{tabular}

Una idea básica extraemos del cuadro: el grupo 3, el de lascas y láminas retocadas, forma el grupo más numeroso de todos, superando a casi más de la mitad de los útiles $(57,35 \%)$. Desde luego, esta característica evidencia un uso importante de los útiles. De hecho, dentro de este grupo, 20 de las 39 piezas contabilizadas presentan retoques de uso.

A continuación les siguen en importancia numérica las muescas y los denticulados (25\%). Ambos útiles son muy abundantes en los yacimientos de la Edad del Cobre. También importantes, aunque con menor porcentaje $(7,35 \%)$, son los útiles que caracterizan a la Edad del Cobre, como son foliáceos, cepillos y elementos de hoz. Curiosamente, y a diferencia de otros yacimientos del valle del Guadalquivir, no se ha hallado ningún elemento de hoz; en cambio sí tenemos 5 foliáceos, entre ellos 2 puntas de flecha. Tampoco hay cepillos. Con parecido porcentaje (10,29\%) aparecen los elementos de tradición paleolítica, con 2 raederas, 2 raspadores y 1 buril. Es interesante resaltar la inexistencia de láminas de borde abatido, geométricos y microburiles (útiles de tradición epipaleolítica). Ausencia que también hemos encontrado en otros poblados calcolíticos como por ejemplo el de Valencina de la Concepción en Sevilla (Ramos 1991-1992:56-7).

\section{FUNCIONALIDAD}

Como decíamos al principio, un artefacto contextualizado arqueológicamente no es más que el resultado de un proceso socio-económico determinado. Desde esta perspectiva, podemos vincular la tecnología dentro de unas relaciones sociales concretas. Para establecer estas relaciones ser humano-naturaleza y las relaciones de los seres humanos entre sí, hay multitud de preguntas que plantear. Responder a para qué sirvieron y cómo se usaron nos ayudará a resolver cuestiones sobre la funcionalidad de los instrumentos de trabajo. Carlos Mazo (1992: 8-11) ha señalado que los mecanismos comúnmente usados para responder a estas cuestiones son: inducción y deducción según la forma del útil y el razonamiento supuestamente lógico; la comparación etnográfica; la experimentación sesgada y limitada, por las pocas variables manejadas; la estadística de las formas de los útiles y de su sustitución y evolución; la distribución de los tipos o clases de útiles en los yacimientos; y el análisis de huellas de uso. De todos ellos, el análisis de huellas de uso o traceológico es el que goza de mayor credibilidad entre los/as investigadores/as. Sin embargo, no deben descartarse otros estudios (estadístico, etnográfico, morfológico, análisis espacial, etc) para plantear hipótesis sobre la funcionalidad de los útiles.

El análisis de huellas de uso "se basa en la observación mediante aparatos ópticos de una serie de huellas o alteraciones que el trabajo a que se ve sometido un útil lítico, produce sobre la superficie de éste" (Mazo 1991: 13). Entre las huellas que podemos encontrar tenemos micropulidos, estrías, residuos, redondeamientos y esquirlamientos de los filos. 
No podemos realizar un estudio funcional de la industria lítica sin la elaboración previa del análisis macroscópico y microscópico del material. En nuestro caso concreto, la ausencia de medios técnicos y económicos impide que este tipo de estudios puedan llevarse a cabo. Somos conscientes de que este tipo de estudios podría aportarnos una interesante información de carácter económico y social, resolviendo cuestiones sobre qué artefactos se usaron y cuáles no, el tipo de materia procesada, la forma de trabajar los instrumentos, qué tareas se realizaron con ellos, qué materias primas preferían para determinados instrumentos, los tipos de enmangamiento que se utilizaban, la duración relativa del trabajo, etc.

A pesar de todo, determinados grupos tipológicos sí parecen según algunos/as investigadores/as, relacionarse con determinadas tareas. Sin embargo deben usarse tan sólo como hipótesis de trabajo.

Las piezas con una funcionalidad más evidente son las puntas de flecha foliáceas, que engarzadas en una vara de madera debían tener una importante misión en las actividades cinegéticas. Como ya señalaban algunos investigadores (McEwen 1991:53) "el arco fue durante milenios el útil más resolutivo de cazadores y guerreros que reflejaban las diversas necesidades del arquero". Ellos plantean que no hay seguridad de que estas puntas, ya usadas desde el Solutrense, sean verdaderas puntas de flecha, también podrían ser puntas de dardos arrojadizos. Un trabajo especializado en el análisis de huellas de uso mostró que las puntas de varios yacimientos han podido ser reutilizadas para otras funciones secundarias para las que fueron creadas (Geneste y Plisson 1990:304). Por tanto, como se evidencia en algunos casos, no puede determinarse con plena seguridad la funcionalidad de un artefacto encontrado en un yacimiento sólo por su morfología. Por ejemplo, un estudio funcional de piezas líticas de Yamanas (Tierra del Fuego) demostró que una punta había servido para raspar hueso y otra para raspar asta (Clemente y Terradas 1993:519). Otro estudio macroscópico y microscópico desarrollado sobre este tipo de piezas tanto experimentales como arqueológicas, ha descubierto dos tipos de huellas que nos corrobora que las puntas de flecha fueron utilizadas como tales (Fischer et alii 1984: 43).

Muy interesante es la alta presencia de lascas y láminas con retoques de uso. En este sentido, José Ramos (1991-1992:57) ha sugerido que las dimensiones y la alta fracturación de la industria lítica estudiada de Valencina de la Concepción podrían indicar su empleo como "hoces". Esto explicaría la ausencia de elementos de hoz en el lugar. Esta circunstancia coincide con el registro arqueológico que presenta el yacimiento de Dolores Quintanilla. De hecho, tenemos la presencia de una lámina con retoques de uso y posible "lustre de cereal". Sin embargo, sabemos de la existencia de elementos de hoz en Carmona durante la Edad del Cobre ${ }^{10}$, que podría combinarse con la utilización de estas lascas y láminas. Quizás, en el yacimiento esta ausencia de elementos de hoz pueda ser casual, aunque no descartamos la explicación de José Ramos. No obstante, la presencia de molinos en este yacimiento nos indica que la agricultura de cereales o su procesado debió constituir una actividad muy importante para la vida de estos grupos humanos. De todas formas, es necesario el análisis traceológico para confirmar el uso de las láminas como hoces. En general, algunos estudios realizados por otros/as investigadores/as sobre láminas con retoques de uso, han demostrado su empleo en el trabajo de plantas duras (Vaughan y Bocquet 1987:504). Patrick Vaughan en un estudio sobre lascas y láminas retocadas ha señalado, tras su análisis traceológico, el uso de estas piezas para "racler des plantes dures", al igual que las lascas y láminas con retoque de uso (ibidem:403).

Otros elementos importantes para el desarrollo de distintas actividades domésticas son los raspadores, denticulados y muescas. Para los raspadores sí existe una correspondencia entre los bordes utilizados y las huellas que aparecen después de trabajar la piel seca de forma transversal (Plisson 1985; MansurFranchomme 1986; Vaughan y Bocquet 1987). Sin embargo, como ya algunos/as investigadores/as señalan, eso no debe ser tomado como una regla (Clemente y Terradas 1993:519; Vaughan 1987:405-406). Las muescas y denticulados siempre son problemáticas. En general, se han relacionado con el trabajo

10. Según nos informó el equipo de investigación de Carmona. 
de la madera y el hueso. Sin embargo, el análisis traceológico de muchas de ellas ha descartado que estas hayan sido utilizadas en alguna tarea (Vaughan y Boquet 1987:403).

Hugues Plisson (1985), al analizar una truncadura oblicua, ha señalado su posible uso para ranurar materiales minerales.

A pesar de todo lo dicho, no podemos asegurar qué tareas fueron desarrolladas por las piezas estudiadas. Algunos trabajos han demostrado que hay útiles que tienen un carácter polifuncional y además han servido para tratar distintas materias, de ahí que un simple estudio morfo-tipológico no pueda aportarnos demasiados datos sobre el uso de las piezas.

No debe olvidarse que muchos de los llamados "restos de talla" (nos referimos concretamente a las lascas y láminas sin retoque) no son considerados "instrumentos de trabajo", de ahí que en los inventarios se excluyan del grupo de "útiles". Sin embargo, estudios de huellas de uso aplicados a los restos de talla han evidenciado que muchos fueron usados como instrumentos de trabajo en distintas tareas.

\section{CONCLUSIONES}

De todo este estudio que hemos realizado sobre el material lítico tallado de una de las estructuras (Fondo 1) de Dolores Quintanilla, podemos extraer una serie de ideas:

1. Observamos en relación con la materia prima que hay un uso combinado de la cuarcita y el sílex, aunque predominando la primera. Pensamos que el uso tradicional de la cuarcita a lo largo de toda la prehistoria del Bajo Guadalquivir se puede explicar por:

- La abundancia de cantos rodados de río de cuarcita en esta zona del valle del Guadalquivir (Carmona), que ha sido una fuente inagotable de materias primas.

- La calidad de la cuarcita permite producir instrumentos de trabajo con morfologías muy variadas.

- En general, el tipo de útil que se fabrica en cuarcita es el que tradicionalmente se ha realizado sobre esta materia desde el Paleolítico.

En cuanto a las rocas silíceas, como a menudo ocurre en las industrias prehistóricas del Bajo Guadalquivir, no tenemos muchos datos sobre su procedencia; desde luego, no parece que esta materia prima abunde en las inmediaciones del yacimiento que estamos estudiando. Sólo tenemos constancia de la existencia de algunos guijarros o cantos pequeños en afloramientos del Aljarafe (Ramos 1991-92: 44). Algunas de las tipometrías de hojas fabricadas en sílex harían pensar en una procedencia más lejana, tal vez del Subbético de Cádiz o Málaga.

El estudio en profundidad por parte de los/as petrólogos/as nos ayudaría a identificar claramente las materias primas elegidas para la elaboración de los instrumentos de trabajo, inferir las fuentes de extracción o recolección, e incluso los intercambios de materias primas.

2. Por otra parte, destaca un alto porcentaje de restos de talla y útiles en el yacimiento. Es posible que en este lugar se hayan realizado también algunas de las fases de la cadena operativa o proceso productivo lítico, además del uso de algunos útiles en diferentes tareas domésticas. De esta forma, se puede explicar el elevado número de piezas propias de la talla (nódulos, núcleos, desechos, esquirlas y descortezados) para la fabricación de los útiles.

3. En general, hay un dominio de las técnicas de talla, desde las más simples a las que requieren una mayor complejidad técnica, como evidencian las hojas de talla a presión y las puntas de flecha.

4. Una de las características del conjunto lítico es su poca homogeneidad en cuanto a la calidad técnica. De manera que muchas de las piezas (si la ponemos en relación con períodos anteriores) son más difíciles de clasificar tipológicamente. Este hecho coincide con la tónica general de este período, en el que hay un mayor descuido por las formas. 
5. La industria lítica, tanto en cuarcita como en sílex, es de mediano y pequeño tamaño en su mayoría, según observamos de los núcleos y restos de talla. Esto puede ser indicativo de que la materia prima procede de nódulos. Sin embargo, las mayores piezas se reservan para láminas con retoques abruptos de sílex, que tal vez procedan de lugares de extracción mucho más lejanos y especializados en esta materia prima.

6. El alto grado de fracturación de la industria podría relacionarse con el uso continuado y su posterior abandono. Sin embargo, es una hipótesis que habría que plantearse con otros datos: por un lado, los procedentes de la excavación; y por otro a través del análisis traceológico o de huellas de uso de las piezas.

7. El análisis de los útiles por grupos culturales nos señala entre otros elementos cómo se mantienen los productos considerados de tradición paleolítica (raspadores, buriles y raederas).

8. El análisis global de la industria lítica nos inclinaría a enmarcarla durante la segunda mitad del III milenio a.n.e. ("Cobre Pleno") por:

- el mantenimiento de piezas que son del substrato paleolítico;

- la existencia de retoque plano de algunas piezas, como son las puntas de flecha y los foliáceos;

- el porcentaje de piezas con retoques abruptos $(11 \%)$ y aquellas que tiene retoques simples $(16 \%)$;

— las puntas de flecha de base cóncava;

- y el uso de la técnica de la talla a presión.

En definitiva, el estudio que aquí ofrecemos es el principio, no el final, del estudio de los instrumentos de trabajo de piedra tallada del yacimiento de la calle Dolores Quintanilla. Análisis futuros, entre otros petrológicos y traceológicos, así como su relación con el resto de las estructuras que aparecen y de los datos arqueográficos del yacimiento, nos ayudarán a inferir cuestiones sobre los instrumentos de trabajo: cómo se fabricaron, cómo se usaron, sobre qué materias, en qué condiciones, para qué, qué necesidades cubrían, quiénes las trabajaban, cómo se repartían las materias primas, de dónde extrajeron las materias primas, quiénes las transportaban, cómo se repartían, etc. Intentamos inferir el modo de vida ${ }^{11}$ de esta formación económico-social a partir de los modos de trabajos ${ }^{12}$ de dicha formación. Con este proyecto y su desarrollo podemos y debemos contribuir en la explicación y profundización de los procesos de transformación de los grupos humanos que habitaron el territorio de Carmona durante la segunda mitad del III milenio a.n.e.

\section{BIBLIOGRAFÍA}

BAGOLINI, B. (1968): "Ricerche sulle dimensioni dei manufatti litici prehistorici non ritocatti", Annali dell'Unversité di Ferrara. Sezione XV, vol. I, $\mathrm{n}^{\circ} 10$, p.195-219. Ferrara.

BATE, L.F. (1989): "Notas sobre el materialismo histórico en la arqueología", Boletín de Antropología Americana, $\mathbf{n}^{\circ} 19$, México.

CLEMENTE, I y TERRADAS, X. (1993): "Matiéres premieres et fonctions: l'exemple de l'outillage lithique des Yamanas (Terra de Feu)", Traces et fonction: les gestes retrouvés, Colloque internacional de Liège, Eraul, vol. 50.

DOMÍNGUEZ-BELLA, S.; GRACÍA PRIETO, J. y MORATA CÉSPEDES, D. (1995): “Estudio geológico del yacimiento del río Palmones (Algeciras, Cádiz)", en RAMOS, J. (dir.)El Paleolítico Superior Final

11. El modo de vida es la expresión particular de una Formación Económico Social (Bate 1989). Para definirlo tenemos que ayudarnos de la totalidad del proceso productivo (medios productivos, procesos de trabajo, productos del trabajo y formas de consumo) (Vargas 1990).

12. El modo de trabajo puede definirse como el conjunto de instrumentos, medios de producción y procesos de trabajo que caracterizan a una unidad social (Vargas 1990). 
del río Palmones (Algeciras, Cádiz). Un ejemplo de la tecnología de las comunidades especializadas de cazadores-recolectores. Instituto de Estudios Gibraltareños. Algeciras (Cádiz).

FISCHER, A.; HANSEN, P.V. y RESMUSSEN, P. (1984): "Macro and Micro Wear on Lithic Projectile Points. Experimental Results and Prehistoric Examples", Journal of Danish Archaeology, vol. 3, pp. 19-46.

GENESTE, J.M. y PLISSON, H. (1990): “Technologie fonctionelle des pointes a cran solutreennes: l'apport des nouvelless donnes de la grotte de Combe Sauniere (Dordogne)", Eraul 42, Liège.

MANSUR-FRANCHOMME, M.E. (1986): Microscopie du materiel lithique préhistorique. C.N.R.S. Paris.

MAZO, C. (1992): Glosario y cuerpo bibliografía de los estudios funcionales en prehistoria. Monografía Arqueológica, 34. Universidad de Zaragoza.

MCEWEN, E. (1991): "Diseño y construcción de los arcos primitivos" Investigación y Ciencia, n⿳179.

MORA, R.; MARTÍNEZ MORENO, J. y TERRADAS, X. (1992): "Un proyecto de análisis: el Sistema Lógico Analítico (S.L.A)", Tecnología y Cadenas Operativas Líticas, 15-18 enero 1991, Treballs d'Arqueologia.

RAMOS, J. (1991-1992): "La industria lítica del Cobre Pleno del poblado de Valencina de la Concepción (Sevilla)", Norba 11-12: 43-74.

RAMOS, J.; VALVERDE, M.; ALMAGRO, A y ROMERO, J.L. (1992): "Tecnología lítica de la Edad del Cobre y Bronce en la Marisma del Cuervo (Jerez de la Frontera, Cádiz)", Spal 1:151-177, Sevilla.

RUIZ, A.; NOCETE, F.; MOLINOS, M. y CASTRO, M. (1986): "El concepto de producto en Arqueología" Arqueología Espacial $\mathrm{n}^{\circ} 7$, vol.1, pp.63-80, Teruel.

TERRADAS, X. (1995): Las estrategias de gestión de los recursos líticos del Prepirineo catalán en el IX milenio BP: el asentamiento prehistórico de la Font del Ros (Berga, Barcelona).Treballs d'Arqueologia, $\mathrm{n}^{\circ} 3$, Departament d'Història de les Societats Pre-capitalistes i d'Antropología Social de la Universitat Autònoma de Barcelona.

PIE, J. y VILA, A. (1991): "Relaciones entre objeto y materiales en el estudio de la industria lítica", Tecnología y cadenas Operativas Líticas: 271-278, Universidad Autónoma de Barcelona, 15-18 enero de 1991, Treballs d'Arqueologia

PLISSON, H. (1985): "Contribution de la tracéologie a la localisation des aires d'activité et d'occupation", $L^{\prime}$ Anthropologie, $t$. 89, $\mathrm{n}^{\circ}$ 4, pp. 473-478. Paris.

VARGAS, I. (1990): Arqueología. Ciencia y Sociedad. Ed. Abre Brecha, Caracas.

VAUGHAN, P. y BOCQUET, A. (1987): "Première étude fonctionnelle d'outils lithiques néolithiques du village de Charavines, Isère", $L^{\prime}$ Anthropologie, t. 91, n² 2, pp. 399-410. 


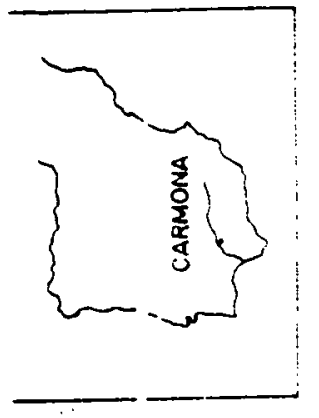

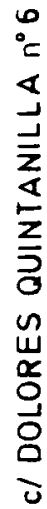
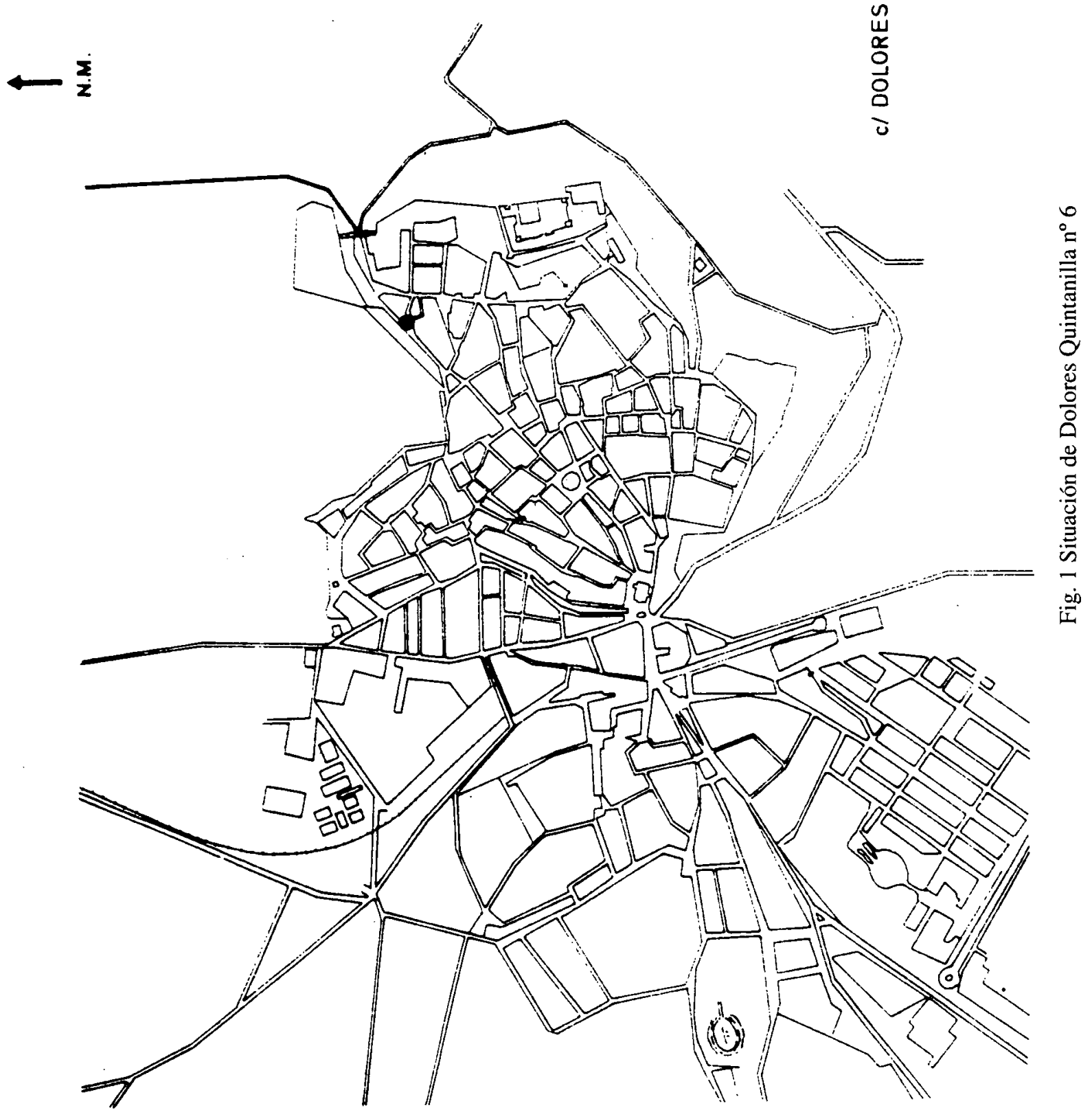


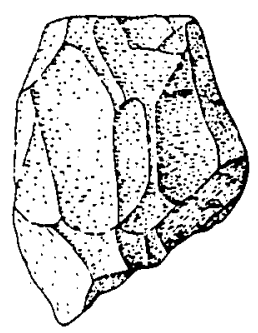

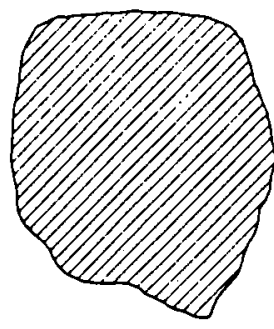

1
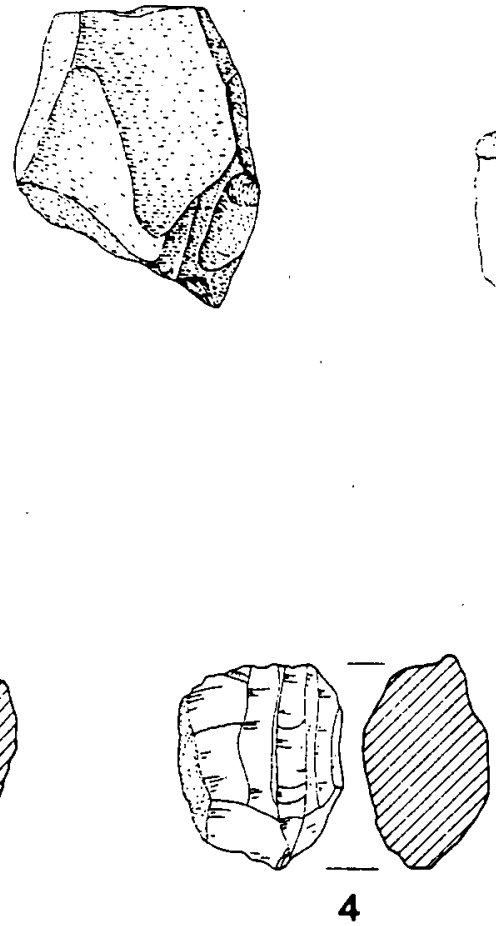

3

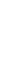

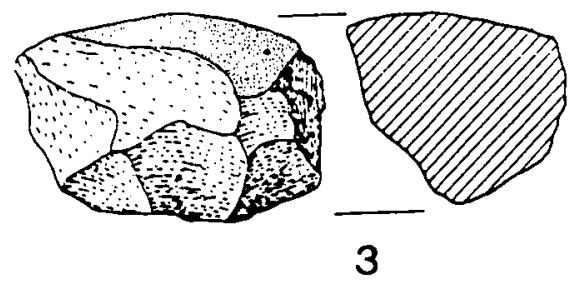

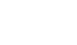

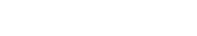

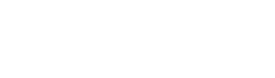
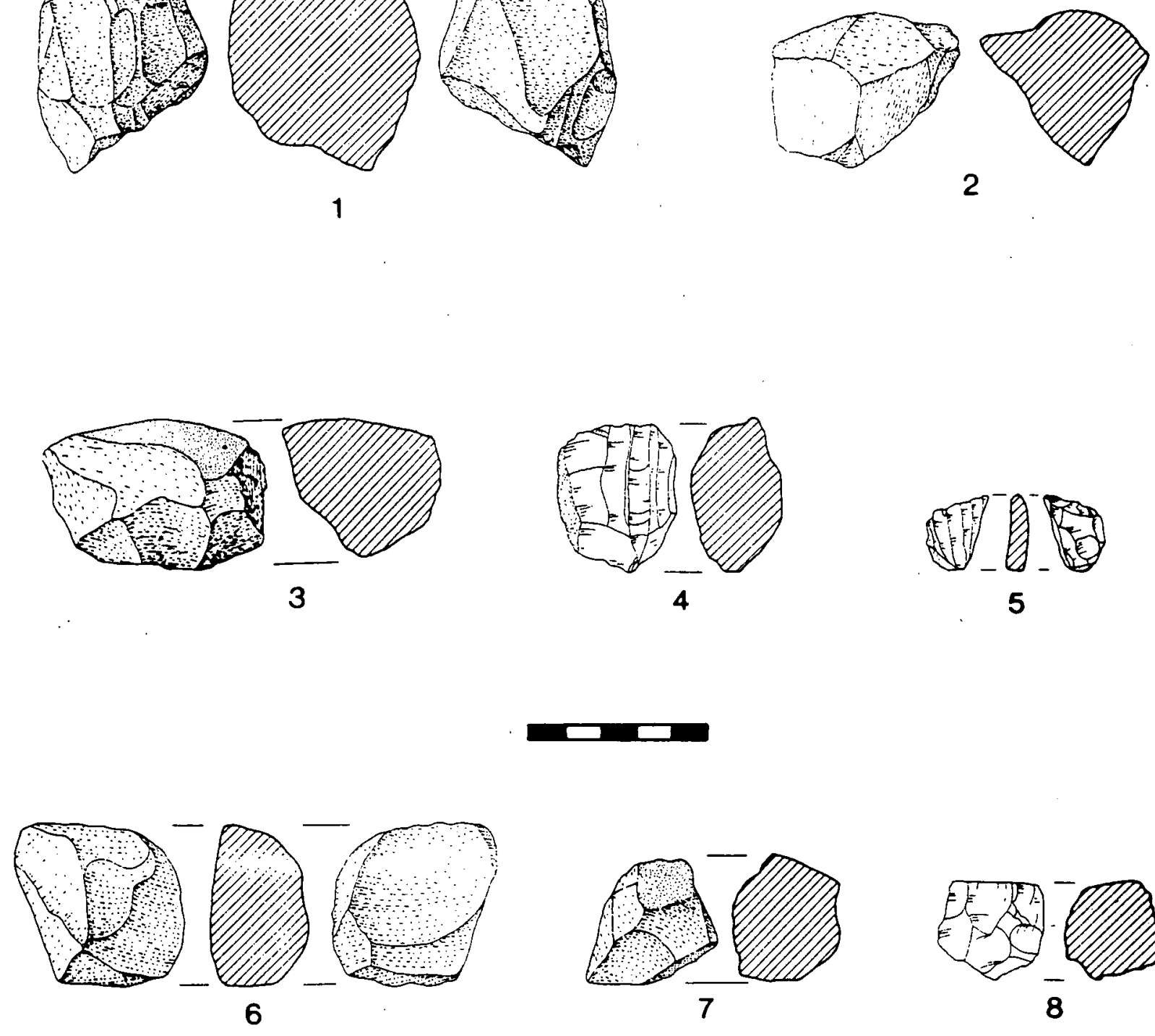

2

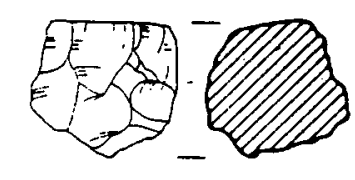

8
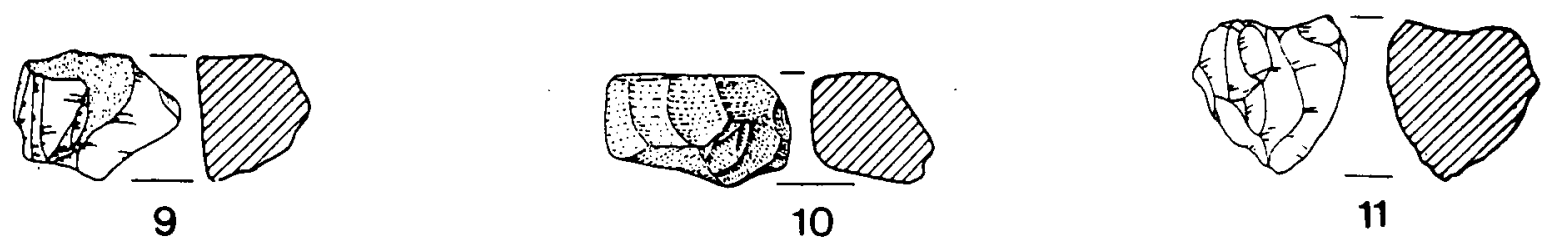

Fig. 2 Dolores Quintanilla $n^{\circ}$ 6. Restos de talla: núcleos poliédricos $(1,2)$; diversos $(3,6,7,9)$; para hojas $(4,5,11)$; prismáticos $(8,10)$ 


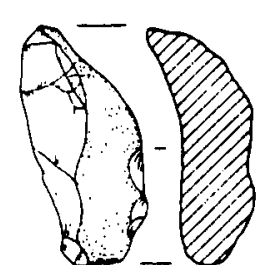

$-1$

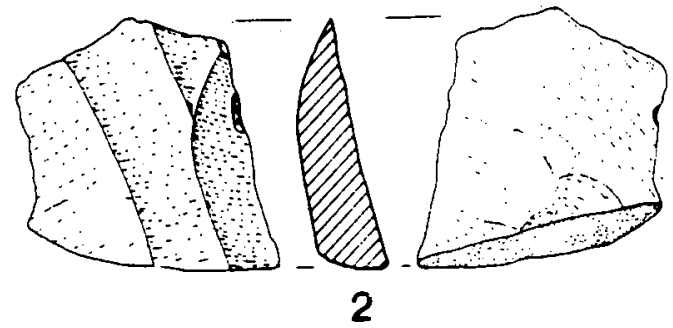

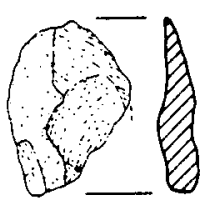

3

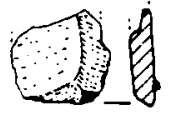

8
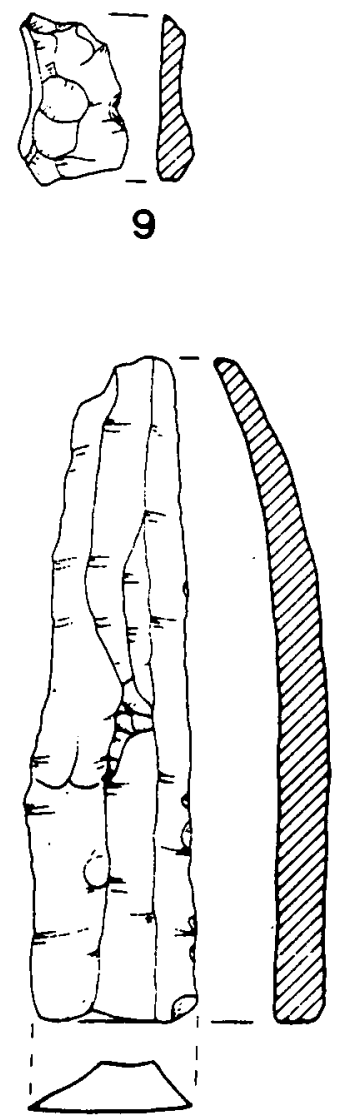

15

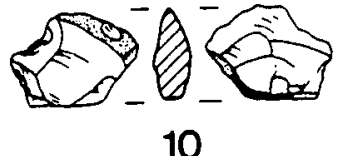

10

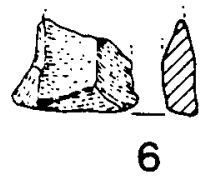

6

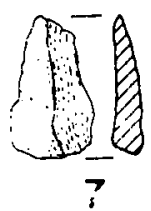

$?$

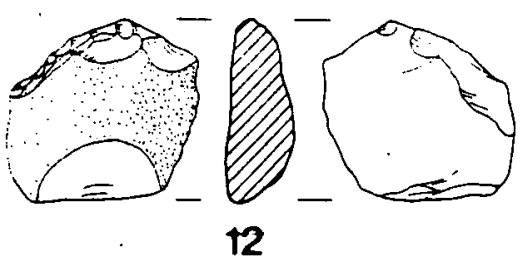

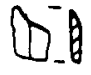

11

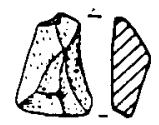

13

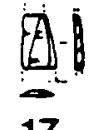

17

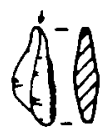

14

OD-B

$\triangle$
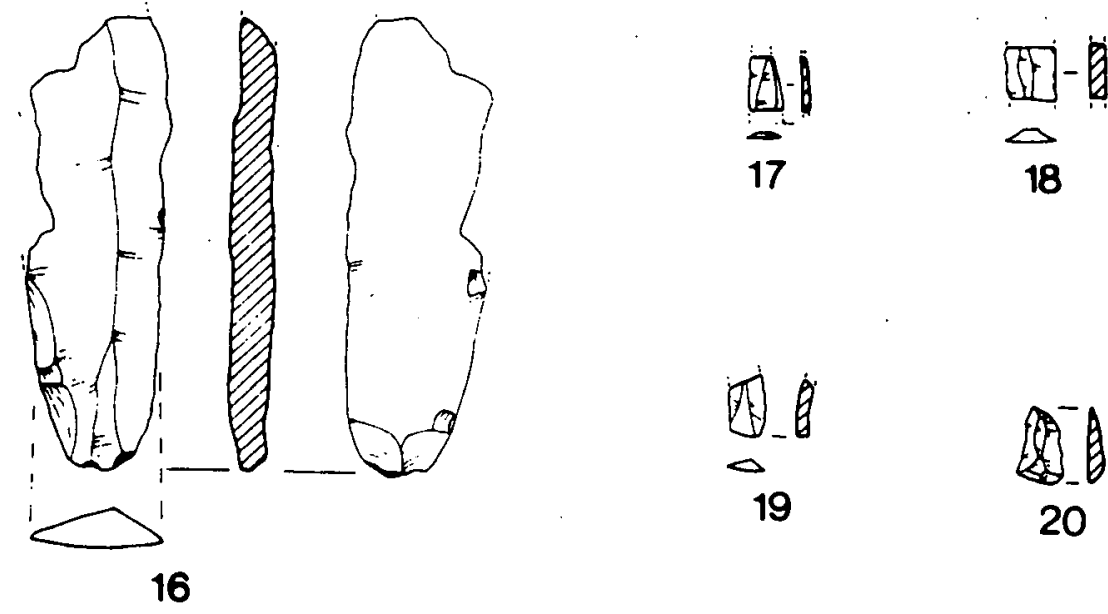

20

Fig. 3 Dolores Quintanilla ${ }^{\circ}$ 6. Restos de talla: lascas semicorticales $(1,2,3,5,7)$; lascas internas $(4,6,8,13,17,20)$; hojas $(15,16)$; hojitas (18 19). Útiles: muesca (9); muesca retocada (10); truncadura (11); raspador simple (12); buril (14) 

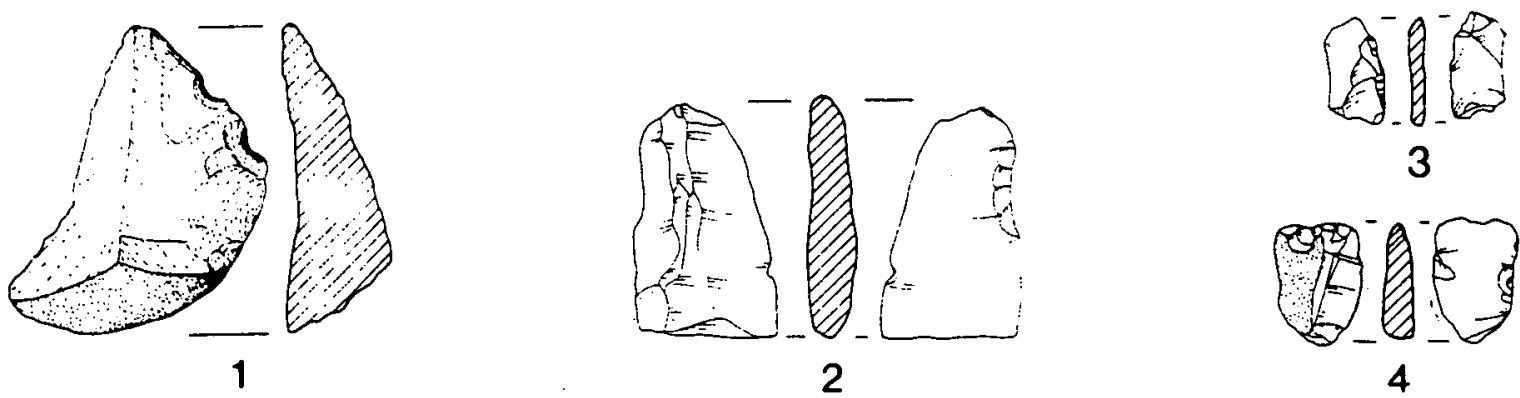

3

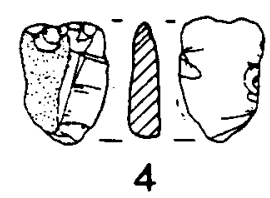

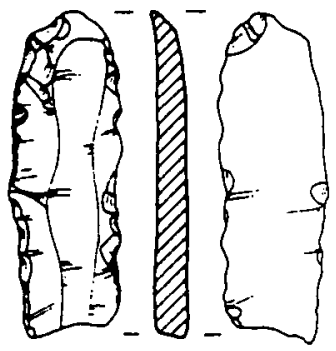

5

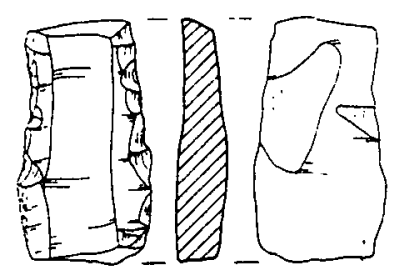

6
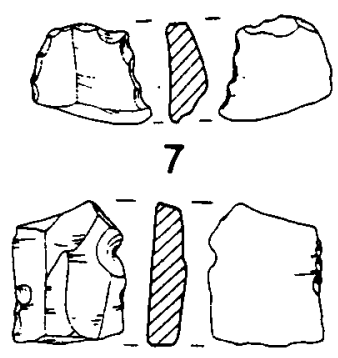

8

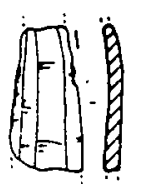

10

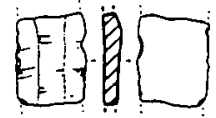

11

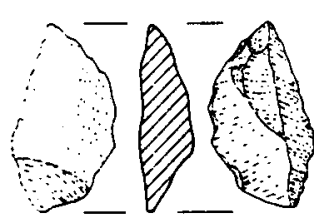

12

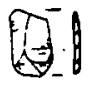

13
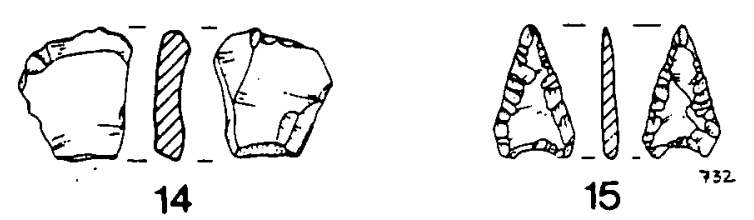

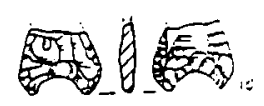

16

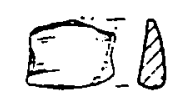

17

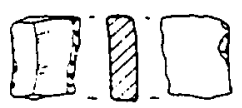

18

Fig. 4 Dolores Quintanilla ${ }^{\circ} 6$. Útiles: muesca (1); lasca con retoques simples $(2,3,14)$; láminas y lascas con retoque de uso $(4,9,10,11,12,13,17)$; láminas con retoques abruptos $(5,6,18)$; denticulado (7); retoque simple (8); puntas de flecha foliáceas $(14,15)$. 

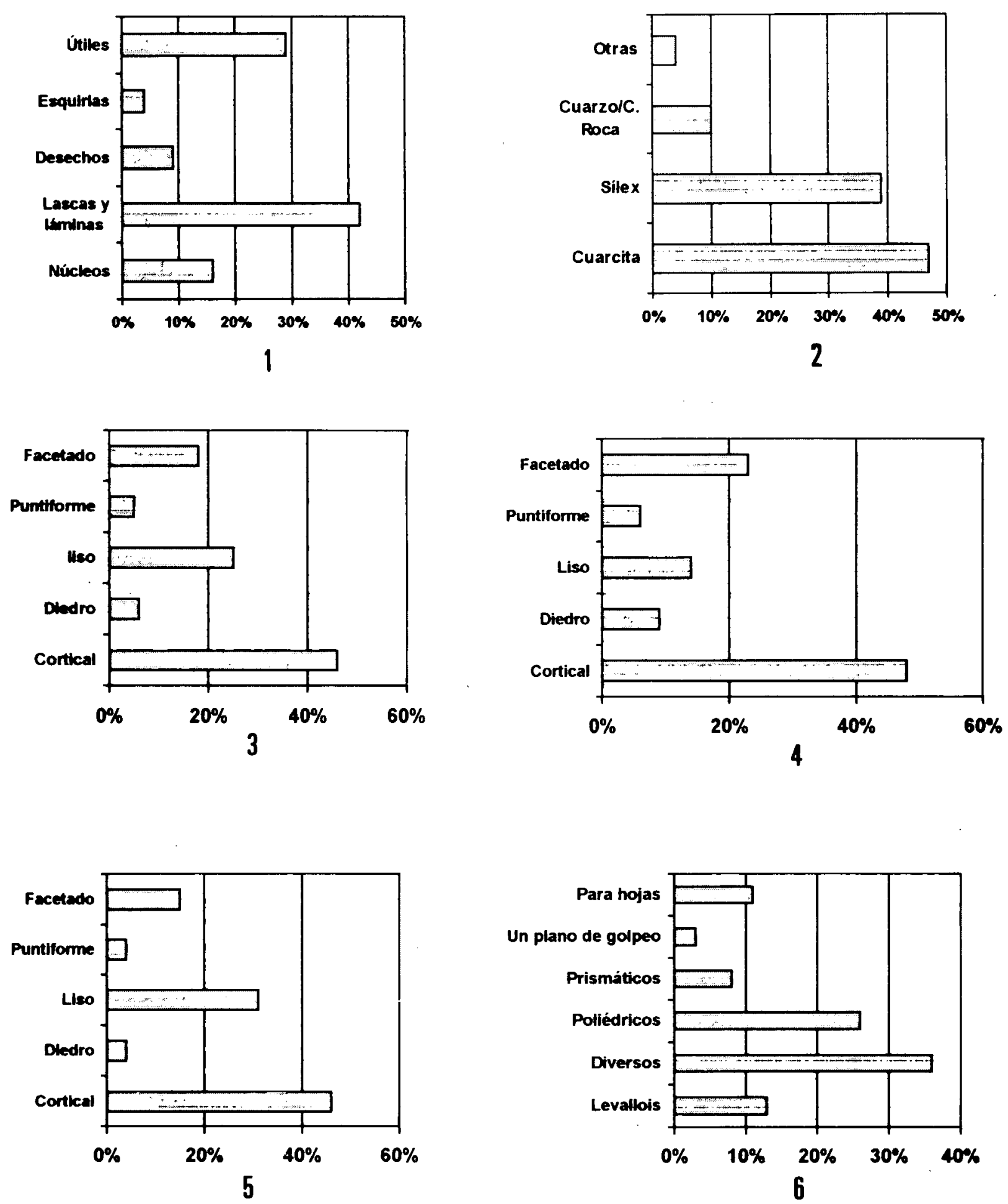

Fig. 5 Dolores Quintanilla ${ }^{\circ}$ 6. Gráficas: Cómputo general de la industria (1); Tipos de materias primas (2); Tipos de talones reconocibles del total (3); Tipos de talones reconocibles de los útiles (4); Tipos de talones reconocibles de los restos de talla (5); Tipo de núcleos (6). 

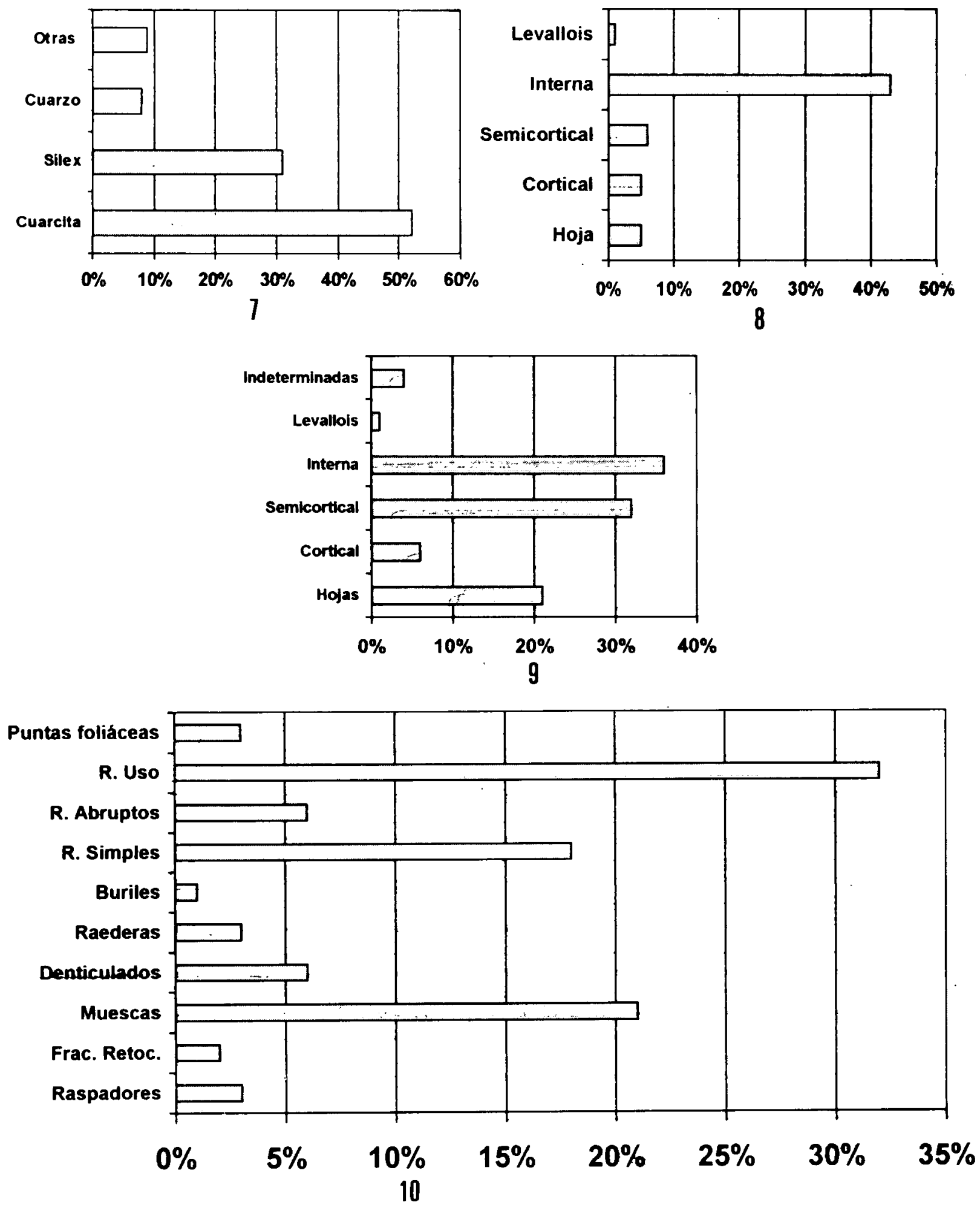

Fig. 6 Dolores Quintanilla $\mathrm{n}^{\circ}$ 6. Gráficas: Materia prima de los núcleos (7); Tipos de lascas y láminas sin retocar (8); Tipos de lascas y láminas retocadas (9); Cómputo General de los útiles (10). 